\title{
THE EFFECTIVENESS AND SAFETY OF MYCOPHENOLATE MOFETIL IN LUPUS NEPHRITIS
}

by

MAZEN ELYAN, MD

Submitted in partial fulfillment of the requirements

for the degree of Master of Science

Thesis Adviser: Dr. Barbara Cromer

Clinical Research Scholars Program

CASE WESTERN RESERVE UNIVERSITY

May 2008 


\section{CASE WESTERN RESERVE UNIVERSITY \\ SCHOOL OF GRADUATE STUDIES}

We hereby approve the thesis/dissertation of

Mazen Elyan

candidate for the Master of Science degree *.

(signed) Barbara Cromer, MD

(chair of the committee)

Stanley Ballou, MD

Steven Lewis, MS MBA

(date) $3 / 10 / 2008$

*We also certify that written approval has been obtained for any proprietary material contained therein. 


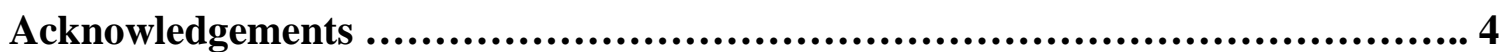

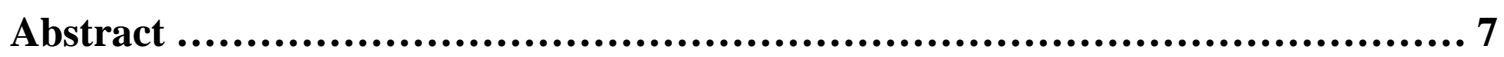

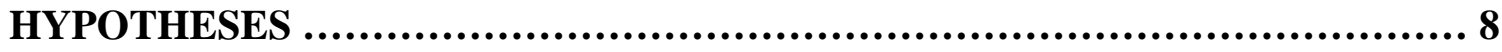

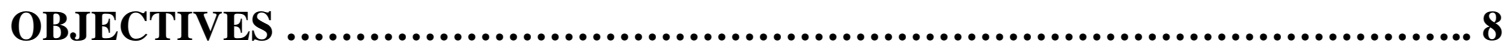

BACKGROUND AND SIGNIFICANCE $\ldots \ldots \ldots \ldots \ldots \ldots \ldots \ldots \ldots \ldots \ldots \ldots \ldots \ldots \ldots \ldots \ldots . . . \ldots 10$

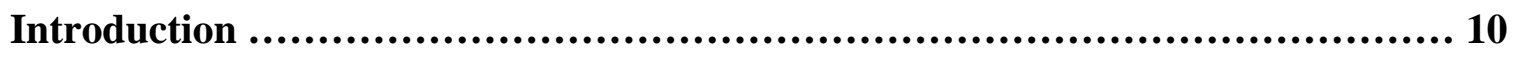

Diagnosis of Systemic Lupus Erythematosus and Lupus Nephritis ................ 11

Goals of Treatment of Lupus Nephritis ........................................ 15

Definition of Remission of Lupus Nephritis .................................... 15

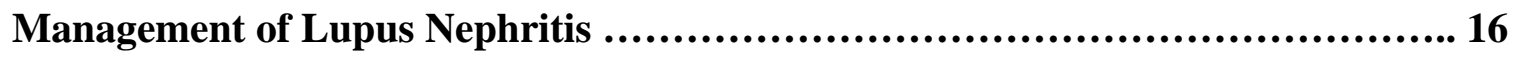

Induction therapy for lupus nephritis ....................................... 17

Corticosteroids .............................................................. 17

Cyclophosphamide regimens.................................................... 18

Mycophenolate mofetil ....................................................... 19

Maintenance of remission of lupus nephritis ................................... 24

Limitations of Current Data ..................................................... 26 
Adjunctive Therapies for Lupus Nephritis

Clinical Predictors of Outcome of Lupus Nephritis

MATERIALS AND METHODS 28

Design and Setting 28

Participants 28

Intervention 29

Definitions and outcome measures 30

Data Management Procedures 31

Statistical Methods 33

RESULTS 33

Baseline Characteristics at Induction Phase 33

Outcomes 36

Primary outcome measure 36

Secondary outcome measures 37

Maintenance therapy

Adverse events .45

DISCUSSION 46 


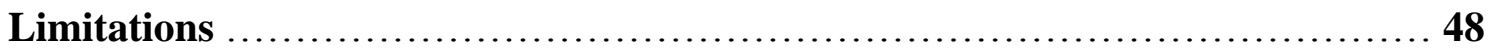

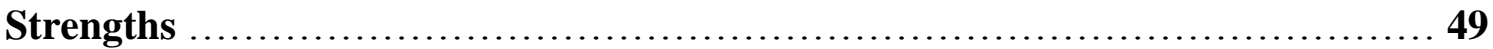

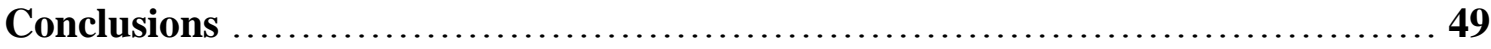

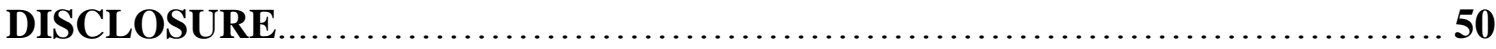

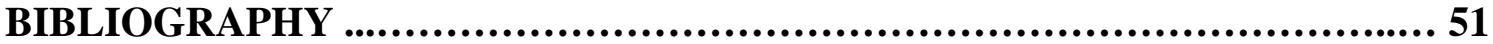




\section{Acknowledgements}

I am grateful to the following teachers and mentors, for their help regarding this study and my career development:

Stanley Ballou, MD for generating the idea for this study, directing its development, and mentoring my research

Barbara Cromer, MD for support and great advice throughout the course of the Clinical Research Scholars Program and guidance on preparing this document

Steven Lewis, MS MBA for assistance as a member of my thesis committee

Alfred Connors, MD for inspiration and unlimited support of this step of my career 


\section{List of Tables}

Table 1: The American College of Rheumatology classification criteria for Systemic

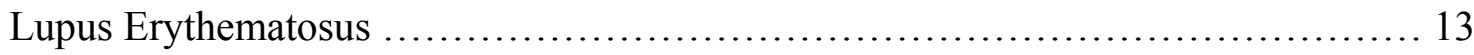

Table 2: The International Society of Nephrology and the Renal Pathology Society

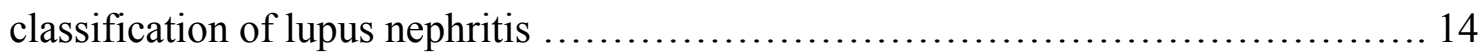

Table 3: Studies that evaluated MMF for induction of remission of lupus nephritis.... 23

Table 4: Studies that evaluated MMF for induction of remission of lupus nephritis.... 25

Table 5: Categorical variables at the beginning of induction therapy $\ldots \ldots \ldots \ldots \ldots \ldots 35$

Table 6: Continuous variables at the beginning of induction therapy................. 36

Table 7: Laboratory values over time ..................................... 38

Table 8: Categorical variables correlation with complete remission............... 41

Table 9: Continuous variables correlation with complete remission $\ldots \ldots \ldots \ldots \ldots \ldots \ldots 42$

Table 10: Categorical variables correlation with at least partial remission........... 43

Table 11: Continuous variables correlation with at least partial remission ........... 44

Table 12: Adverse Events ................................................... 46 


\section{List of Figures}

Figure 1: Prednisone dose over time - induction phase .......................... 39 


\section{The Effectiveness and Safety of Mycophenolate Mofetil in Lupus Nephritis}

\section{Abstract}

by

\section{MAZEN ELYAN, MD}

Objective: To evaluate the effectiveness and safety of Mycophenolate Mofetil (MMF) in lupus nephritis (LN).

Methods: A retrospective study of $25 \mathrm{LN}$ patients consecutively treated with MMF. The primary outcome was complete renal remission $(\mathrm{CR})$ : urine protein/creatinine $\leq 0.5 \mathrm{~g} / \mathrm{g}$, inactive urine sediment and stable serum creatinine within ${ }^{<} 15 \%$ above baseline.

Results: 57\% achieved CR (Median time 8.5 months). CR was correlated with MMF dose and LN duration. Of 13 patients who had $\mathrm{LN}$ for $<12$ months and took $\geq 2$ grams/day of MMF, 11 achieved CR, versus 1 of 8 patients who did not meet both criteria ( $\mathrm{p}=0.002$ ). $87 \%$ of patients maintained remission (Median follow-up: 20 months) while taking MMF. Most adverse events were transient and did not require therapy changes.

Conclusions: MMF is effective and safe for induction and/or maintenance of remission of LN. Early treatment with $\geq 2$ grams/day is essential for optimal outcome. CR may take $>6$ months. 


\section{HYPOTHESES}

1. Mycophenolate mofetil, combined with corticosteroids, is an effective treatment for induction of remission of moderate to severe lupus nephritis.

2. Mycophenolate mofetil is effective for maintenance of remission of lupus nephritis.

3. Mycophenolate mofetil is generally safe and well tolerated in patients with lupus nephritis.

\section{OBJECTIVES}

\section{Primary Objectives}

1. To assess the effectiveness of Mycophenolate mofetil combined with corticosteroids in inducing remission of moderate to severe lupus nephritis.

2. To assess the effectiveness of Mycophenolate mofetil for maintaining remission of lupus nephritis.

3. To assess the tolerability and safety of Mycophenolate mofetil in patients with lupus nephritis.

\section{Secondary Objectives}

1. To determine patterns of response to Mycophenolate mofetil when used for induction of remission of lupus nephritis.

2. To identify potential predictors of remission of lupus nephritis with the use of Mycophenolate mofetil. 
3. To assess outcome of induction therapy with Mycophenolate mofetil beyond the initial phase of treatment.

4. To evaluate changes in laboratory and immunological markers of lupus activity during treatment with Mycophenolate mofetil for induction of remission.

5. To evaluate the steroid sparing effect of Mycophenolate mofetil. 


\section{BACKGROUND AND SIGNIFICANCE:}

\section{Introduction:}

Systemic Lupus Erythematosus (SLE) is a chronic rheumatic disease, characterized by the production of auto-antibodies and occurrence of a wide spectrum of clinical manifestations (Table 1). SLE primarily affects women of child bearing age although it can occur at any age and in men. In the United States the prevalence of SLE among adult women is estimated to be at least $0.1 \%$ (1). SLE occurs 10 times more commonly in women than in men and about 3 times more commonly in black women than in white women (2).

Lupus nephritis, or kidney involvement in SLE, is a serious manifestation that can lead to kidney failure and premature death. It is estimated to affect at least $27 \%$ of SLE patients, with higher rates in Hispanics (35\%), African Americans (40\%) and Asians (59\%) than in whites (18\%) and in younger patients (Age less than 33 years at lupus diagnosis) (3). Lupus nephritis remains one of the most common causes of mortality in patients with SLE despite the advances in immunosuppressive therapy, improvements in dialysis, and renal transplantation (4)

The optimal therapeutic regimen for lupus nephritis and duration of treatment remain uncertain. Monthly intravenous cyclophosphamide for at least 6 months has been viewed as the "standard of care" for induction therapy for severe lupus nephritis (5), but this regimen fails to induce complete remission in up to $57 \%(6)$ of patients, and is associated with serious adverse effects that can include severe infections, bone marrow suppression, premature gonadal failure, heqmorrhagic cystitis and malignancy. 
In the last decade, mycophenolate mofetil (MMF) has emerged as another option for induction of remission of moderate to severe lupus nephritis, with recent data suggesting better renal and overall outcomes compared to cyclophosphamide (7). Moreover, MMF has recently been shown to be more effective than quarterly intravenous cyclophosphamide for maintenance of remission of lupus nephritis, with fewer adverse effects (8).

The literature on lupus nephritis treatment is limited in the number of clinical trials, number of patients studied and duration of follow up. Randomized clinical trials that compared cyclophosphamide combined with corticosteroids to corticosteroids alone included only a total of 228 patients (5). Randomized clinical trials that compared MMF to cyclophosphamide for induction therapy in adults included only a total of 268 patients to date; all have been short term with duration of $6-12$ months (9).

Available data do not justify declaring any current regimen as the "standard of care" for lupus nephritis. In fact, there is currently no immunosuppressive agent that is approved by the Food and Drug Administration for the treatment of this condition.

\section{Diagnosis of Systemic Lupus Erythematosus and Lupus Nephritis}

The diagnosis of SLE is usually made by the presence of multisystem disease and evidence of autoimmunity. It is supported by the presence of 4 of the 11 American College of Rheumatology classification criteria $(10,11)$. According to these criteria, lupus nephritis is clinically defined by persistent proteinuria of greater than 0.5 grams per day (or greater than $3+$ by semi quantitation on a random urine specimen) or the presence of active urine sediment (defined by the presence of cellular casts, which may be red cell, 
hemoglobin, granular, tubular, or mixed casts). However, proteinuria is not specific as it can be related to other conditions such as diabetes and hypertension. Therefore, it has been proposed that, in the absence of kidney biopsy, another supporting finding of active lupus should be present, such as active urinary sediment, positive anti double stranded deoxyribonucleic acid (anti ds DNA) antibodies and / or low serum complement components $\mathrm{C} 3$ and $\mathrm{C} 4$ (12).

The initial clinical presentation of lupus nephritis ranges from asymptomatic proteinuria, to variable peripheral edema and hypertension, to rapidly progressive renal failure with elevated blood urea nitrogen and serum creatinine as signs of more severe disease. Hypoalbuminemia is common. Low complement components $\mathrm{C} 3$ and $\mathrm{C} 4$ levels and elevated anti DNA antibody titers are found in a majority of patients and often correlate with activity of lupus nephritis. Lupus nephritis is currently classified histopathologically according to the World Health Organization (WHO) classification, most recently revised by the International Society of Nephrology and the Renal Pathology Society (13) (Table 2). The role of routine kidney biopsy has been debated and some clinicians have questioned the additional value of the biopsy over physician judgment based on a compilation of clinical and laboratory findings $(14,15)$. Some authors advise performing biopsy when the diagnosis or prognosis is not clear, thus possibly avoiding unnecessary aggressive immunosuppression (16-18). In any case, whether a kidney biopsy is performed or not, treatment decisions are best based on the overall picture of each individual case. 
Table 1: The American College of Rheumatology classification criteria for Systemic Lupus Erythematosus

Criterion Definition

1. Malar rash Fixed erythema, flat or raised, over the malar eminences, tending to spare the nasolabial folds

2. Discoid rash Erythematous raised patches with adherent keratotic scaling and follicular plugging; atrophic scarring may occur in older lesions

3. Photosensitivity Skin rash as a result of unusual reaction to sunlight, by patient history or physician observation

4. Oral ulcers $\quad$ Oral or nasopharyngeal ulceration, usually painless, observed by physician

5. Arthritis Non erosive arthritis involving 2 or more peripheral joints, characterized by tenderness, swelling, or effusion

6. Serositis a) Pleuritis: convincing history of pleuritic pain or rubbing heard by a physician or evidence of pleural effusion $O R$ b) Pericarditis: documented by ECG or rub or evidence of pericardial effusion

7. Renal disorder a) Persistent proteinuria greater than 0.5 grams per day or grater than $3+$ if quantitation not performed $O R$ b) Cellular casts: may be red cell, hemoglobin, granular, tubular, or mixed

8. Neurologic $\quad$ a) Seizures: in the absence of offending drugs or known metabolic derangements; e.g., uremia, disorder ketoacidosis, or electrolyte imbalance $O R$ b) Psychosis: in the absence of offending drugs or known metabolic derangements, e.g., uremia, ketoacidosis, or electrolyte imbalance

9. Hematologic disorder

a) Hemolytic anemia: with reticulocytosis $O R$ b) Leukopenia: less than 4,000/mm3 total on 2 or more occasions $O R$ c) Lyphopenia: less than $1,500 / \mathrm{mm} 3$ on 2 or more occasions $O R \mathrm{~d}$ ) Thrombocytopenia: less than $100,000 / \mathrm{mm} 3$ in the absence of offending drugs

10. Immunologic disorder

a)Anti DNA antibody: antibody to native DNA in abnormal titer $O R$ b) Anti Sm: presence of antibody to Smith nuclear antigen $O R$ c) Positive finding of anti phospholipid antibodies based on 1) an abnormal serum level of IgG or IgM anticardiolipin antibodies, 2) a positive test result for lupus anticoagulant using a standard method, or 3) a false positive serologic test for syphilis known to be positive for at least 6 months and confirmed by Treponema pallidum immobilization or fluorescent treponemal antibody absorption test.Standard methods should be used in testing for the presence of antiphospholipid.

11. Antinuclear An abnormal titer of antinuclear antibody by immunofluorescence or an equivalent assay at any antibody point in time and in the absence of drugs known to be associated with "drug-induced lupus" syndrome

The proposed classification is based on 11 criteria. For the purpose of identifying patients in clinical studies, a person shall be said to have systemic lupus erythematosus if any 4 or more of the 11 criteria are present, serially or simultaneously, during any interval of observation. 
Table 2: The International Society of Nephrology and the Renal Pathology Society classification of lupus nephritis

\begin{tabular}{|c|c|}
\hline Class & Description \\
\hline $\begin{array}{l}\text { I (Minimal mesangial } \\
\text { lupus nephritis) }\end{array}$ & $\begin{array}{l}\text { Light microscopy reveals normal glomeruli } \\
\text { Immunofluorescence reveals mesangial immune deposits. }\end{array}$ \\
\hline $\begin{array}{l}\text { II (Mesangial } \\
\text { proliferative lupus } \\
\text { nephritis) }\end{array}$ & $\begin{array}{l}\text { Light microscopy reveals mesangial hypercellularity and / or } \\
\text { mesangial matrix expansion. }\end{array}$ \\
\hline $\begin{array}{l}\text { III (Focal proliferative } \\
\text { lupus nephritis) }\end{array}$ & $\begin{array}{l}\text { Light microscopy reveals segmental (less than } 50 \% \text { of the tuft) } \\
\text { or global (more than } 50 \% \text { of the tuft) endo capillary or extra } \\
\text { capillary glomerulonephritis in fewer than } 50 \% \text { of glomeruli, } \\
\text { associated with mesangial involvement. }\end{array}$ \\
\hline $\begin{array}{l}\text { IV (Diffuse } \\
\text { proliferative lupus } \\
\text { nephritis) }\end{array}$ & $\begin{array}{l}\text { Light microscopy reveals segmental or global endo capillary or } \\
\text { extra capillary glomerulonephritis in more than } 50 \% \text { of } \\
\text { glomeruli, with necrotizing lesions, in addition to mesangial } \\
\text { involvement, commonly associated with sub endothelial } \\
\text { deposits. Segmental (IV S) and global (IV G) diffuse lupus } \\
\text { nephritis are defined by more than } 50 \% \text { of affected glomeruli } \\
\text { having segmental and global lesions, respectively. }\end{array}$ \\
\hline $\begin{array}{l}\text { V (Membranous lupus } \\
\text { nephritis) }\end{array}$ & $\begin{array}{l}\text { Light microscopy, immunofluorescence and electron } \\
\text { microscopy reveal sub epithelial immune deposits or their } \\
\text { sequelae. }\end{array}$ \\
\hline $\begin{array}{l}\text { VI (Advanced } \\
\text { sclerosing lupus } \\
\text { nephritis): }\end{array}$ & More than $90 \%$ of glomeruli are globally sclerosed. \\
\hline
\end{tabular}

Class III or IV can co-exist with class V, and are designated as combined disease (e.g., class III and V, or class IV and V).

Patients with lupus nephritis can have tubulo interstitial nephritis, thrombotic microangiopathy, vascular disease and renal disease associated with drug-induced lupus, as well as renal diseases unrelated to lupus (e.g., diabetes). 


\section{Goals of Treatment of Lupus Nephritis:}

The ultimate goal of management of lupus nephritis is to prevent end stage renal disease and reduce mortality. The first step to achieve this is to induce clinical remission of nephritis as defined below, ideally as soon as possible following disease onset. Another goal of treatment is to induce immunological remission.

Data have shown that clinical remission, even if only partial, is associated with markedly improved renal and overall survival $(6,19)$. The survival rate at five and 10 years was 95 $\%$ in patients who achieved remission, compared to $69 \%$ at five years and $60 \%$ at 10 years in those who did not achieve remission (6).

After achieving clinical remission, either complete or partial, the long term goal is to prevent flares of lupus nephritis. Renal flares have been shown to be the strongest predictor of progression to end stage renal disease (20).

\section{Definition of Remission of Lupus Nephritis}

The definition of remission of lupus nephritis remains controversial. In practice, clinical remission is defined by resolution of proteinuria, hematuria, pyuria, and cellular casts, and an improvement or at least stabilization of the serum creatinine. Immunological remission is defined by normalization of serum complement component $\mathrm{C} 3$ and $\mathrm{C} 4$ levels and disappearance of anti dsDNA antibody.

There are flaws in this definition:

First, Persistent hematuria may not necessarily reflect active lupus nephritis as several other causes such as structural damage of the glomeruli, renal cysts or 
cyclophosphamide-induced hemorrhagic cystitis may be accountable. However, the presence of dysmorphic red cells and / or cellular casts suggests an active disease. Similarly, pyuria may reflect may reflect disorders other than lupus nephritis, such as infection, etc.

Second, proteinuria usually responds much more slowly to treatment than other markers of the illness. This fact may create difficulties in determining response to treatment, especially in patients with membranous lupus nephritis, in whom other clinical and serological markers of activity are commonly absent. Moreover, there is lack of agreement regarding the level of proteinuria that can be considered acceptable, in view of other physiologic and pathologic influences such as physical activity, fever, etc. Some clinical studies have demonstrated that proteinuria can be still present after six months of induction therapy in patients who ultimately achieve remission, as documented by resolution of proteinuria and urine sediment abnormalities $(8,19-22)$.

Moreover, successful induction of clinical remission is not always associated with normalization of serum creatinine, as irreversible sclerosis of the glomeruli or vascular changes can exist (or perhaps progress) despite resolution of inflammation $(23,24)$.

Because of such uncertainties, a kidney biopsy may be helpful in determining the status of lupus nephritis with regard to activity or chronicity at the pathologic level.

\section{Management of Lupus Nephritis:}

Several controlled clinical trials from the NIH (National Institutes for Health) and other centers over the past three decades have demonstrated the superiority of regimens 
including cyclophosphamide (and possibly azathioprine) compared with steroids alone, at least for initial treatment of active lupus nephritis. Cumulative data from long term studies has also confirmed the value of maintenance immunosuppressive therapy, though the most appropriate agent, dose, and duration of treatment remain unclear. In view of recognition of the prognostic importance of renal flares on long term disease outcome, the current treatment paradigm for treatment of lupus nephritis has changed to a twofold approach: 1. Initial induction of clinical remission; and 2. Long-term maintenance.

\section{Induction therapy for lupus nephritis:}

\section{Corticosteroids:}

Corticosteroids inhibit both acquired and innate immunologic function. They suppress a wide range of immune responses mediated by $\mathrm{T}$ and $\mathrm{B}$ lymphocytes. They are also powerful suppressors of the effector functions of monocytes and neutrophils. The anti inflammatory effects of steroids are mediated by recruitment of transcription factors to promoter sequences of genes coding for anti inflammatory gene products and inhibition of inhibiting the synthesis and secretion of inflammatory cytokines (25). They are remarkably efficacious in managing many of the acute disease manifestations of inflammatory and autoimmune disorders. However, corticosteroids are notorious for many adverse effects that include but are not limited to increased risk of infections, diabetes, hypertension, osteoporosis, hypothalamic pituitary adrenal axis suppression, avascular necrosis and impaired wound healing. These side effects correlate with both dose and duration of treatment. Therefore, steroid sparing immunosuppressive agents are commonly used in chronic autoimmune diseases. 
Oral prednisone is routinely used as a part of the induction regimen (26). The usual starting dose is 0.5 to $1.0 \mathrm{mg}$ per $\mathrm{kg}$ per day, which is often continued for several weeks and then tapered by 10 to $20 \%$ every one to two weeks initially and then much more slowly when the dose approaches $10 \mathrm{mg}$ per day to a minimum dose that is adequate to control the extra renal manifestations. In patients with more severe disease (such as the presence of rapidly progressive renal failure), high dose intravenous "pulse" methylprednisolone (500 to $1000 \mathrm{mg}$ given over 30 minutes for three days) is often used. Occasionally, monthly methylprednisolone pulses are given with monthly intravenous cyclophosphamide for six months because of the finding of a benefit of combining cyclophosphamide with methylprednisolone in the long term NIH trial (26). However, steroid treatment alone even with pulse methylprednisolone has clearly been shown to be inferior in inducing remission, with a remission rate of only $29 \%$ in patients who received IV pulse methylprednisolone alone in the NIH trial (27).

\section{Cyclophosphamide regimens:}

Cyclophosphamide is a cytotoxic alkylating agent, which exerts its biologic activity by binding and cross linking of several molecules including DNA, RNA, and proteins. This impairs DNA copying and transcription, leading to death of the cell or a change in its function. Consequently, the absolute numbers of $\mathrm{B}$ and $\mathrm{T}$ lymphocytes decrease and their function declines (28). The immunosuppressive effects of cyclophosphamide correlate with the dose and duration of treatment.

When compared to corticosteroids alone, adding cyclophosphamide has been shown to result in better renal survival as measured by stabilization of serum creatinine; however, overall survival was not significantly different. In contrast, adding azathioprine, 
compared to corticosteroids alone had no impact on renal survival, although interestingly, it has been shown to result in better overall survival (5). A long term trial at the NIH showed that cyclophosphamide alone or combined with methylprednisolone resulted in significantly better renal survival compared to methylprednisolone alone. However, overall mortality was better with steroids alone (4\%) than with cyclophosphamide either alone $(19 \%)$ or in combination with methylprednisolone (18\%). Moreover, cyclophosphamide alone was significantly inferior to cyclophosphamide combined with methylprednisolone (26).

A meta analysis of randomized controlled trials of immunosuppressive treatments for lupus nephritis pointed out some of the adverse effects associated with cyclophosphamide (5). Ovarian failure was a major problem, affecting about half of women treated with cyclophosphamide plus corticosteroids. Serious infections occurred in $20 \%$ of the patients. Ineffectiveness of cyclophosphamide as initial treatment was noted in a substantial minority of patients, evident by occurrence of end-stage renal disease in $16 \%$ of patients and a high mortality rate of $21 \%$.

\section{Mycophenolate mofetil (MMF)}

MMF is an immunosuppressive drug that was first introduced for the prevention of acute and chronic rejection of solid organ allografts as well as for treatment of acute rejection episodes in the mid 1990s. Since then, it has been used in a variety of autoimmune diseases. MMF is an orally administered, highly bio-available ester pro drug of mycophenolic acid, which is a highly selective, non competitive, and reversible inhibitor of inosine 5(')-monophosphate dehydrogenase, the rate limiting enzyme in the de novo 
biosynthesis of guanosine nucleotides. As a result, mycophenolic acid inhibits RNA, DNA and protein synthesis. It suppresses the production of pro inflammatory cytokines, nitric oxide, and LDH in macrophages and inhibits proliferation and recruitment of both $\mathrm{T}$ and $\mathrm{B}$ lymphocytes as well as the monocytes $(29,30)$. It also has an anti proliferative effect on non immune cells, fibroblasts and vascular smooth muscle cells (31). Mycophenolic acid is five fold more potent inhibitor of the type II isoform of inosine monophosphate dehydrogenase (mainly expressed in activated T and B lymphocytes) than of the type I isoform (expressed in other cell types) (32).

Mycophenolate mofetil has been investigated as a potential substitute to cyclophosphamide for induction of remission of lupus nephritis, since it exerts more selective immunosuppressive properties compared to cyclophosphamide. Recent studies, summarized below, suggest that it may be as or even more effective and less toxic compared with cyclophosphamide.

(Table 3) summarizes studies that evaluated MMF for induction of remission of lupus nephritis; all studies that included at least 15 patients treated with MMF were reported. Of note, corticosteroids were used concurrently in all patients.

An open label, non inferiority, multicenter randomized clinical trial compared oral MMF (initial dose, $1 \mathrm{~g}$ per day, titrated up to $3 \mathrm{~g}$ per day) with monthly intravenous cyclophosphamide in the induction phase of active lupus nephritis treatment. Outcome measures were evaluated at 24 weeks. Of 140 patients enrolled in the study, 71 received MMF and 69 received cyclophosphamide. All patients received concurrent oral corticosteroids. In the intent to treat analysis, $22.5 \%$ of patients receiving MMF achieved complete remission compared with only $5.8 \%$ of patients receiving cyclophosphamide ( $\mathrm{P}$ 
value $=0.005$ ). Rates of partial remission were not statistically significantly different at $29.6 \%$ in the MMF group and $24.6 \%$ in the cyclophosphamide group. None of the patients who received MMF died, compared to 3 of the patients who received cyclophosphamide; two of these died during protocol therapy. MMF was associated with fewer severe infections and hospitalizations but with increased incidence of diarrhea (21).

A small randomized controlled trial from Hong Kong randomized 42 patients with diffuse proliferative lupus to a regimen of MMF (initial dose of $1 \mathrm{gm}$ twice daily) and corticosteroids given for one year, or to a regimen of cyclophosphamide and corticosteroids given for 6 months, followed by azathioprine and corticosteroids for 6 months. Outcome measures were evaluated after one year. Of twenty one patients treated with MMF and corticosteroids, $81 \%$ achieved complete remission, and $14 \%$ achieved partial remission, compared with $76 \%$ and $14 \%$, respectively, of the 21 patients in the other group. There was a trend toward fewer infections in the MMF group. Amenorrhea, alopecia, leucopenia and death occurred only in the cyclophosphamide group. The rates of lupus nephritis flares were $15 \%$ and $11 \%$ in patient who received mycophenolate mofetil and cyclophosphamide, respectively (22). An extended five year follow up study included an additional twenty two patients (33). Thirty three patients received MMF, and 31 received the cyclophosphamide followed by azathioprine treatment, both in combination with corticosteroids. More than $90 \%$ in each group achieved at least partial remission after the induction regimen. Serum creatinine remained stable and comparable in the two groups over time as did improvements in proteinuria and serology. Doubling of serum creatinine occurred in $6.3 \%$ of the patients treated with MMF and in $10.0 \%$ of the patients treated with cyclophosphamide followed by azathioprine. Lupus nephritis 
flares occurred in 11 and 9 patients, respectively. MMF treatment was associated with significantly fewer infections and infections that required hospitalization. Four patients in the cyclophosphamide / azathioprine group but none in the MMF group reached the composite end point of end stage renal failure or death ( $\mathrm{P}$ value $=0.062$ by survival analysis).

A systematic review of four randomized trials and observational studies found that, when compared with cyclophosphamide, MMF was associated with significantly higher rates of complete remission and at least partial remission, and lower rates of death and hospitalization. MMF was significantly associated with less serious infections, leucopenia, amenorrhea and alopecia but with increased incidence of diarrhea (7).

A more recent meta analysis of randomized trials that compared MMF with cyclophosphamide for induction therapy in adult patients with lupus nephritis found that the pooled relative risk for failure to induce remission for MMF compared with cyclophosphamide was 0.70 and the relative risk for the composite outcome of death or end stage renal disease was 0.44 . Adverse events, especially leucopenia and amenorrhea, occurred more frequently in patients treated with cyclophosphamide (9).

The optimal dose of MMF for treatment of lupus nephritis is not known. Data from renal transplant indicate good outcome with 2 grams per day. However, a dose of 3 grams per day was noted to be associated with better outcome in African American patients (34). Pharmacokinetics and metabolism of MMF do not change dramatically in patient with renal insufficiency although it may be affected in patients with advanced renal insufficiency as well as in hypoalbuminemia (35). 
Table 3: Studies that evaluated MMF for induction of remission of lupus nephritis

\begin{tabular}{|c|c|c|c|c|c|c|}
\hline Study (design) & Location & Duration & $\begin{array}{l}\text { No of } \\
\text { patients }\end{array}$ & $C R$ & $P R$ & Note \\
\hline $\begin{array}{l}\text { Kasitanon N (36) } \\
\text { (OBS) }\end{array}$ & USA & 12 months & MMF 29 & $38 \%$ & NR & $\begin{array}{l}10 \text { patients with pure membranous } \\
\text { nephritis with } 40 \% \mathrm{CR} \text { at one year }\end{array}$ \\
\hline $\begin{array}{l}\text { Borba EF et al (37) } \\
(\mathrm{OBS})\end{array}$ & Brazil & 18 months & MMF 20 & $55 \%$ & $100 \%$ & $\begin{array}{l}\text { Lupus nephritis with isolated } \\
\text { severe proteinuria }\end{array}$ \\
\hline $\begin{array}{l}\text { Ginzler (21) } \\
(\mathrm{RCT})\end{array}$ & USA & 6 months & $\begin{array}{l}\text { MMF } 71 \\
\text { CYC } 69\end{array}$ & $\begin{array}{l}22.5 \% \\
5.8 \%\end{array}$ & $\begin{array}{l}52.2 \% \\
30.4 \%\end{array}$ & $\begin{array}{l}\text { Severe infection only in CYC } \\
\text { Pyogenic infection less in MMF } \\
\text { Diarrhea more in MMF }\end{array}$ \\
\hline Cross (38) (OBS) & UK & 12 months & MMF 24 & $83 \%$ & $91.7 \%$ & \\
\hline Chan (33) (RCT) & $\begin{array}{l}\text { Hong } \\
\text { Kong }\end{array}$ & 12 months & $\begin{array}{l}\text { MMF } 33 \\
\text { CYC } 33\end{array}$ & $\begin{array}{l}72.7 \% \\
74.2 \%\end{array}$ & $\begin{array}{l}96.9 \% \\
96.8 \%\end{array}$ & $\begin{array}{l}\text { Follow up was extended at } 28.3 \pm \\
7.2 \text { month in } 12 \text { patients }\end{array}$ \\
\hline Ong (39) (RCT) & Malaysia & 6 months & $\begin{array}{l}\text { MMF } 19 \\
\text { CYC } 25\end{array}$ & $\begin{array}{l}26 \% \\
12 \%\end{array}$ & $\begin{array}{l}58 \% \\
52 \%\end{array}$ & $\begin{array}{l}\text { Differences in efficacy or adverse } \\
\text { events were not significant }\end{array}$ \\
\hline $\begin{array}{l}\text { Kapitsinou (40) } \\
\text { (OBS) }\end{array}$ & Greece & 15 months & MMF 18 & $55.6 \%$ & $77.8 \%$ & 13 patients had failed CYC \\
\hline $\mathrm{Li}(41)(\mathrm{OBS})$ & China & 6 months & MMF 75 & NS & NS & $\begin{array}{l}26 \text { patients were refractory to } \\
\text { treatment of steroids and CYC. } \\
\text { Proteinuria decreased from }(4.24 \\
+/-2.66) \mathrm{g} / \mathrm{d} \text { to }(1.54+/-1.60) \mathrm{g} / \mathrm{d} \\
\text { at } 6 \text { months }(6 \text { mos, } \mathrm{P}<0.01) . \\
\text { Renal function impairment present } \\
\text { in some of the patients also showed } \\
\text { marked improvement. }\end{array}$ \\
\hline $\mathrm{Hu}(42)(\mathrm{OBS})$ & China & 6 months & $\begin{array}{l}\text { MMF } 23 \\
\text { CYC } 23\end{array}$ & NS & NS & $\begin{array}{l}\text { All patients receiving MMF were } \\
\text { those who failed or relapsed after } \\
\text { treatment with steroid combined } \\
\text { with CYC } \\
50 \% \text { reduction of urinary protein } \\
\text { and urinary red blood cells from } \\
\text { baseline value in } 69.6 \% \text { and } 91.3 \\
\% \text { in the MMF Group, in } 47.8 \% \\
\text { and } 65.2 \% \text { in the CYC Group }\end{array}$ \\
\hline
\end{tabular}

CR: complete remission. PR: at least partial remission. OBS: observational study. RCT: randomized controlled trial. CYC: cyclophosphamide. NS: not specified. NR: not reported 


\section{Maintenance of remission of lupus nephritis:}

Relapse of lupus nephritis is common, especially in patients with more severe disease (43). The flare rate after discontinuation or reduction of the immunosuppressive agent has been reported to range from 5.4 to 15.6 per 100 patient years (44). Therefore it is widely accepted that patients should continue to receive immunosuppressive therapy after achieving remission to prevent flares and consequently decrease the risk of progression to end stage renal disease. There are limited data regarding the relative efficacy of the different maintenance regimens. The use of quarterly intravenous cyclophosphamide has been questioned. Maintenance with MMF or azathioprine has been shown to be more effective and safer than a 3 monthly intravenous cyclophosphamide reigmen (8). In this study that included a vast majority of African Americans and Hispanic patients, 59 lupus nephritis patients received induction therapy with monthly boluses of intravenous cyclophosphamide and corticosteroids. Subsequently, the patients were randomly assigned to one of three maintenance therapies: quarterly intravenous injections of cyclophosphamide, oral azathioprine, or oral MMF for one to three years. The 72 month event free survival rate for the composite end point of death or chronic renal failure was significantly higher in the MMF and azathioprine groups (90\% and $80 \%$, respectively) compared to the cyclophosphamide group (45\%). The rate of relapse free survival was higher in the MMF group than in the cyclophosphamide group $(\mathrm{P}$ value $=0.02)$. This study was not powered to detect a difference in effectiveness between MMF and azathioprine. The incidence of hospitalization, amenorrhea, infections, nausea, and vomiting was significantly lower in the MMF and azathioprine groups than in the cyclophosphamide group. 
A meta analysis of randomized clinical trials found that, for maintenance therapy of patients with severe lupus nephritis, there was no significant difference between MMF and azathioprine in prognosis or the risks of amenorrhoea and herpes zoster (45).

Although such data suggest that MMF is comparable with azathioprine, cumulative data from the kidney transplant literature show significantly better overall survival in patients who took MMF compared with those who took azathioprine, even after controlling for transplant rejection and renal function (46). This is perhaps the result of other potentially beneficial non renal effects of MMF including direct inhibition of vascular smooth muscle cell proliferation (47), which might imply an effect on cardiovascular mortality, the major cause of death in patients with SLE.

(Table 4) summarizes studies that evaluated MMF for maintenance of remission of lupus nephritis; all studies that included at least 15 patients treated with MMF were reported.

Table 4: Studies that evaluated MMF for maintenance of remission of lupus nephritis

\begin{tabular}{|c|c|c|c|c|c|}
\hline $\begin{array}{l}\text { Study } \\
\text { (design) }\end{array}$ & Location & Duration & No of patients & $\begin{array}{l}\text { Renal } \\
\text { relapse }\end{array}$ & Note \\
\hline $\begin{array}{l}\text { Chan (33) } \\
\text { (RCT) }\end{array}$ & $\begin{array}{l}\text { Hong } \\
\text { Kong }\end{array}$ & $\begin{array}{l}12 \text { months in } 20 \\
\text { patients } \\
28.3 \pm 7.2 \text { months } \\
\text { in } 12 \text { patients }\end{array}$ & $\begin{array}{l}\text { MMF } 32 \\
\text { CYC/AZA } 30\end{array}$ & $\begin{array}{l}33.3 \% \\
30 \%\end{array}$ & $\begin{array}{l}\text { Patients who received MMF did so for } \\
\text { both induction and maintenance. } \\
\text { Median follow up } 63 \text { months } \\
\text { Significantly less leucopenia, alopecia, } \\
\text { amenorrhea and infections with MMF }\end{array}$ \\
\hline $\begin{array}{l}\text { Contreras } \\
\text { (8) (RCT) }\end{array}$ & USA & 29 months & $\begin{array}{l}\text { MMF } 19 \\
\text { CYC } 17 \\
\text { AZA } 19\end{array}$ & $\begin{array}{l}15.8 \% \\
47.1 \% \\
31.6 \%\end{array}$ & $\begin{array}{l}\text { All patients were treated with CYC for } \\
\text { induction } \\
\text { Study included predominantly } \\
\text { Hispanics and African Americans }\end{array}$ \\
\hline
\end{tabular}

RCT: randomized clinical trial. MMF: mycophenolate mofetil. CYC: cyclophosphamide. AZA: azathioprine 


\section{Limitations of Current Data:}

Some of the limitations of previous studies on MMF in lupus nephritis include the following:

Some studies were of limited quality in terms of allocation concealment and none of them were blinded, but this is difficult to achieve given that the different route of administration for MMF and cyclophosphamide. Patients had different disease severity in different studies and the definition of renal remission varied from one study to another. Most studies were short term while long term follow up studies after induction with MMF included patients who used maintenance therapy with agents other than MMF. Long term maintenance studies with MMF included patients who used cyclophosphamide for induction. Most induction trials have evaluated remission at an arbitrary point of 6 months. Dose of MMF widely ranged between 1 to 3 grams per day for induction and for maintenance. Most reports also do not specify an exact dosage or length of treatment with MMF for either induction or maintenance phases of treatment of severe lupus nephritis. Of note, only 123 patients received MMF in the three "larger" randomized controlled trials of induction therapy of lupus nephritis combined $(21,33,39)$. Only a total of 51 patients received MMF for maintenance of remission of lupus nephritis in the two "larger" randomized controlled trials of $(8,33)$.

Results of some studies especially from Europe and Asia may not be generalizable to the United States population, which includes a significant proportion of patients of African American or Hispanic ethnicity, population groups which may have more severe disease. 


\section{Adjunctive Therapies for Lupus Nephritis:}

Treatment with angiotensin converting enzyme inhibitors and / or angiotensin II receptor blockers is indicated to achieve blood pressure control, ideally below 130 / $80 \mathrm{~mm} \mathrm{Hg}$. This treatment also results in reduction of proteinuria. Such treatment aims at reducing intra-glomerular hypertension, a factor that may contribute to progression to chronic renal failure (48).

Hydroxychloroquine is often used to treat milder forms of SLE and is sometimes stopped in patients with lupus nephritis; however, a small study suggested that it may have an added benefit for renal remission when MMF is used as initial therapy for membranous lupus nephritis (49).

\section{Clinical Predictors of Outcome of Lupus Nephritis:}

Several studies have looked at potential predictors of outcome of lupus nephritis in diverse groups of patients. Racial differences in outcome have been noted. African American and Hispanic patients as well as Asians have been shown to have a worse outcome compared to Caucasians in terms of both renal and overall survival $(6,16,50$ 53). Poor socioeconomic status and lack of medical insurance are also associated with poor outcome in African American and Hispanic patients (53). Several other predictors of worse outcome have been identified in various studies, including: serum creatinine on presentation $(16,54-58)$, nephrotic range proteinuria at baseline (55), duration of nephritis symptoms $>6$ months prior to kidney biopsy (56), diffuse proliferative glomerulonephritis, and tubular atrophy on biopsy $(56,57)$, persistent hypertension $(57$, 
58), and failure to achieve remission $(54,57)$. Delaying treatment has been shown to lead to worse outcome (59).

The primary objective of our study is to evaluate the effectiveness, tolerability and safety of MMF, in combination with corticosteroids, in inducing and / or maintaining remission of lupus nephritis. Secondary aims include determining patterns of response to MMF during the induction phase, identifying potential predictors of remission, and assessing outcome of induction therapy beyond the initial phase.

\section{MATERIALS AND METHODS}

\section{Design and Setting}

We conducted a retrospective observational study of twenty five lupus nephritis patients seen at MetroHealth Medical Center in a dedicated lupus clinic who were consecutively treated with MMF for induction and / or maintenance of remission between December 2000 and October 2006. This study was approved by the MetroHealth Medical Center Institutional Review Board.

\section{Participants:}

\section{Inclusion criteria:}

We included all patients who received MMF at MetroHealth Medical Center lupus clinic during the abovementioned study period, met the American College of Rheumatology 1997 revised classification criteria for Systemic Lupus Erythematosus and had active lupus nephritis as defined by the presence of persistent proteinuria of greater that $500 \mathrm{mg}$ 
per gram creatinine in a random urine sample or greater than $500 \mathrm{mg}$ in a twenty four hour urine collection, in addition to at least one of the following: active urine sediment (defined by the presence of cellular casts and / or greater than 5 red blood cells), positive anti double stranded DNA antibody and / or low serum complement component C3 and / or C4 levels. All patients who received MMF for induction of remission, except two, were consecutive lupus nephritis patients who were cared for by a single rheumatologist and were given MMF as the initial agent. Of the two other patients, one had failed initial cyclophosphamide therapy. The selection of MMF for maintenance was mainly determined by the response to it as an initial induction therapy.

\section{Exclusion criteria:}

No patients were excluded from the study.

\section{Intervention:}

During the induction phase, MMF was administered at a starting dose of $500 \mathrm{mg}$ twice daily and was increased by increments of $500 \mathrm{mg}$ per week to a total daily dose of 2 to 3 grams per day over a few weeks based on the patients' ability to tolerate the medicine. All patients received concomitant corticosteroid therapy at a variable dose with tapering on the basis of clinical improvement. The concurrent use of corticosteroids has been a standard in all studies of lupus nephritis, regardless of the main immunosuppressive agent used.

For maintenance, MMF was prescribed at a fixed dose of 1 gram twice daily in all patients except one, who took 1.5 grams twice daily. 


\section{Definitions:}

\section{The primary outcome:}

The primary outcome measure was complete renal remission as defined by urine protein / creatinine ratio of less or equal to $500 \mathrm{mg}$ per gram, urine analysis with no cellular casts and less than 5 red blood cells, and stable serum creatinine within $15 \%$ above baseline. Baseline creatinine was defined as the value of serum creatinine immediately prior to initiation of MMF.

\section{Secondary outcome measures}

Secondary outcome measures were: [1] partial renal remission as defined by: greater than $50 \%$ improvement in the abnormal renal measurements without worsening (within less than $15 \%$ ) of any single measurement; [2] renal flare defined as increase of greater than $50 \%$ of baseline urine protein / creatinine ratio and / or increase in serum creatinine of greater than $20 \%$ of baseline; and [3] adverse events. Other secondary outcome measures were corticosteroid dose at 3 and 6 months, and final values of urine protein / creatinine ratio, serum creatinine, serum albumin, anti double stranded DNA antibody titers, and complement component $\mathrm{C} 3$ and $\mathrm{C} 4$ levels. We also determined time to normalization of serum creatinine (to less than or equal to $1 \mathrm{mg}$ per deciliter) and to initial improvement in proteinuria defined by at least $30 \%$ reduction in urine protein / creatinine ratio.

Relevant baseline variables included: Demographics (race, gender, and age at diagnosis of lupus nephritis); relevant comorbid disorders (uncontrolled hypertension, determined by blood pressure higher than 140/90 more than 3 times in the year prior to initiating 
MMF, history of diabetes mellitus, determined by fasting blood glucose greater or equal to $126 \mathrm{mg}$ per deciliter more than once before initiation of treatment); duration of SLE, determined from the first time the patient met the American College of Rheumatology criteria and duration of lupus nephritis, determined from the first time proteinuria of greater than $500 \mathrm{mg}$ per gram creatinine in a random urine sample or greater than $500 \mathrm{mg}$ in a twenty four hour urine collection was documented; and other medications used including angiotensin converting enzyme inhibitors, angiotensin II receptor blockers, hydroxychloroquine, and corticosteroids. Use of prednisone was meticulously tracked by reviewing all notes in electronic medical records.

\section{Data Management Procedures}

Electronic medical records were reviewed by the investigators to identify all eligible patients who met the American College of Rheumatology classification criteria for Systemic Lupus Erythematosus, had lupus nephritis, cared for at MetroHealth Medical Center lupus clinic and received MMF for induction and / or maintenance of remission of lupus nephritis between December 2000 and October 2006. Baseline characteristics and initial laboratory values were determined at the time of initiation of MMF. The entire electronic medical record was thoroughly reviewed from the time of drug start until May 2007. Record review included all clinic and emergency room visit notes, hospitalization records, telephone encounter documentations, laboratory tests and radiographic reports. Data were entered into a standard chart extraction form, which was developed by the investigators based on clinical experience and after reviewing prior studies of lupus nephritis. The chart extraction form was coded and contained no personal identifiers. Patients were de identified using a key that only the investigators have access to. The key 
is kept in a locked file separately from patients' data. The key will be destroyed four years after the study ended.

Our IRB application included a request for a waiver of HIPAA Authorization per 45CFR164.512. We provided justification for the waiver by specifically documenting the following: (1) the use or disclosure of protected health information involves no more than minimal risk to the privacy of individuals, based on, at least, the presence of the following elements: (a) There is an adequate plan to protect the identifiers from improper use and disclosure; (b) There is an adequate plan to destroy the identifiers at the earliest opportunity consistent with conduct of the research, unless there is a health or research justification for retaining the identifiers or such retention is otherwise required by law; and (c) there are adequate written assurances that the protected health information will not be reused or disclosed to any other person or entity, except as required by law, for authorized oversight of the research project, or for other research for which the use or disclosure of protected health information would be permitted by this subpart. (2) The research could not practically be conducted without the waiver or alteration; and (3) the research could not practically be conducted without access to and use of the protected health information. Our IRB application also included a request for a Waiver of Informed Consent per 45CFR46.116 (d) as the protocol detail adequately documented that: (a) the research involves no more than minimal risk to the subjects; (b) the waiver or alteration will not adversely affect the rights and welfare of the subjects; (c) the research could not practically be carried out without the waiver or alteration; and (d) the subjects will be provided with additional pertinent information after participation. 


\section{Statistical Methods:}

The one sample proportions test was used to calculate proportions and $95 \%$ confidence intervals. The paired samples Wilcoxon test was used to compare values before and after treatment with MMF for various laboratory data. Univariate analysis was used to determine outcome correlation with covariates. Differences in the characteristics of responders versus non responders were analyzed using Wilcoxon rank sum test for continuous variables and Fisher's exact test for categorical variables. Continuous variables categorization was attempted at different values to investigate the possibility of association with the outcome and significant cutoffs are reported. However, adjusting for covariates using methods such as multivariate logistic regression was not possible because of the small sample size and the small number of patients with the outcome. A two sided $P$ value was used in all statistical analyses and a $p$ value less than 0.05 was considered significant. We used the statistical software R 2.5.1 and SAS 9.1 to conduct our analysis.

\section{RESULTS}

\section{Baseline Characteristics at Induction Phase (Tables 5 \& 6)}

Most patients were female (86\%). African American patients constituted the largest proportion of our cohort ( $52 \%)$. The majority of patients received concurrent treatment with an angiotensin converting enzyme inhibitor and / or an angiotensin receptor blocker and hydroxychloroquine. All patients received corticosteroids concurrently. Two thirds of the patients underwent a kidney biopsy; of these, $50 \%$ had World Health organization 
class IV diffuse proliferative glomerulonephritis. The values for urine: protein creatinine ratio and serum creatinine at time of MMF initiation were missing in 2 patients; however the presence of active lupus nephritis was confirmed with laboratory values before and after initiation of therapy.

Eighty four percent of the patients had evidence of severe lupus nephritis with elevated serum creatinine ( $>1.0 \mathrm{mg}$ per deciliter) and / or nephrotic range proteinuria ( $>3.5$ grams per gram creatinine). The other 3 patients were considered to have moderately severe lupus nephritis with proteinuria $>2$ grams per gram creatinine but with normal serum creatinine ( $\leq 1.0 \mathrm{mg}$ per deciliter). One of the patients had failed to show any evidence of response to IV cyclophosphamide for 3 months prior to initiation of MMF. Most of our patients were young, with a median age of 26 years. The duration of lupus nephritis was 12 months or more in 6 patients $(29 \%)$. All patients had hypoalbuminemia $(<3.4$ gram per deciliter) at the start. Median initial prednisone dose was $30 \mathrm{mg}$ daily with only one patient receiving 1 gram pulse methylprednisolone daily for 3 days. Initial prednisone dose was $\leq 20 \mathrm{mg}$ per day in 7 patients. 


\begin{tabular}{|c|c|c|c|c|}
\hline \multicolumn{3}{|l|}{ Variable } & Number & Percentage (\%) \\
\hline \multicolumn{3}{|l|}{ Female sex } & 18 & $86 \%$ \\
\hline \multirow{3}{*}{\multicolumn{2}{|c|}{ Race }} & African American & 11 & $52 \%$ \\
\hline & & Caucasian & 5 & $24 \%$ \\
\hline & & Hispanic & 5 & $24 \%$ \\
\hline \multicolumn{3}{|c|}{ History of uncontrolled hypertension } & 4 & $19 \%$ \\
\hline \multicolumn{3}{|c|}{ History of diabetes } & 3 & $14 \%$ \\
\hline \multicolumn{3}{|c|}{ Prior use of cyclophosphamide } & 1 & $5 \%$ \\
\hline \multicolumn{3}{|c|}{ *Use of ACEI or ARB } & 19 & $90 \%$ \\
\hline \multicolumn{3}{|c|}{ Use of hydroxychloroquine } & 19 & $90 \%$ \\
\hline \multirow{4}{*}{$\begin{array}{l}\text { World Health } \\
\text { Organization } \\
\text { class }(\mathrm{N}=14)\end{array}$} & III & & 3 & $22 \%$ \\
\hline & IV & & 7 & $50 \%$ \\
\hline & $\mathrm{V}$ & & 2 & $14 \%$ \\
\hline & $\begin{array}{l} \pm \text { Mix } \\
\text { (mem }\end{array}$ & nous and proliferative) & 2 & $14 \%$ \\
\hline \multicolumn{3}{|c|}{$£$ Nephrotic-range UP: CR $(\mathrm{N}=19)$} & 11 & $58 \%$ \\
\hline \multicolumn{3}{|c|}{ §Abnormal serum creatinine $(\mathrm{N}=19)$} & 12 & $63 \%$ \\
\hline \multicolumn{3}{|c|}{$\begin{array}{l}\text { Nephrotic-range UP: CR or abnormal serum creatinine } \\
(\mathrm{N}=19)\end{array}$} & 16 & $84 \%$ \\
\hline
\end{tabular}

* ACEI (angiotensin converting enzyme inhibitor), ARB (angiotensin receptor blocker)

Nephrotic-range proteinuria was defined by urine protein: creatinine ratio UP: CR $>3$ $\mathrm{g} / \mathrm{g}$.

$\S$ Abnormal serum creatinine was defined as $>1 \mathrm{mg} / \mathrm{dl}, \pm \mathrm{UP}: \mathrm{CR}$ (spot urine protein: creatinine) 


\begin{tabular}{|l|c|c|c|}
\hline \multicolumn{4}{|l|}{ Table 6: Continuous variables at the beginning of induction therapy (N = 21) } \\
\hline Variable & Median & $25^{\text {th }}, 75^{\text {th }} \%$ & Range \\
\hline Age (years) & 26 & 24,40 & $18-55$ \\
\hline Duration of SLE (months) & 22 & 3,72 & $1-264$ \\
\hline $\begin{array}{l}\text { Duration of lupus nephritis } \\
\text { (months) }\end{array}$ & 4 & 3,22 & $1-76$ \\
\hline Prednisone dose (mg / day) & 30 & 20,55 & $2.5-1000$ \\
\hline $\begin{array}{l}\text { Serum creatinine (mg / dl) } \\
\text { (N = 19) }\end{array}$ & 1.1 & $0.95,1.6$ & $0.6-4$ \\
\hline *UP: CR ratio (g / g) (N = 19) & 3.2 & $2.65,6.2$ & $0.8-10.2$ \\
\hline Serum albumin (g / dl) (N = 18) & 2.2 & $2.1,2.8$ & $1.2-3.3$ \\
\hline$£$ Serum C3 (mg / dl) $(\mathrm{N}=19)$ & 79 & 59,92 & $26-120$ \\
\hline §Serum C4 (mg / dl) (N = 19) & 14 & 10,19 & $5-32$ \\
\hline Anti DNA Antibody titer (N = 19) & $1: 20$ & $0,1: 160$ & $0-1: 1280$ \\
\hline
\end{tabular}

* UP: CR: urine protein: creatinine ratio

$£$ C3: complement component C3

$\S \mathrm{C} 4$ : complement component C3

\section{Outcomes:}

Primary outcome:

For remission induction, 21 episodes (in 19 patients) of active, moderate to severe lupus nephritis were treated with MMF. Twelve cases (57\%) achieved complete remission (95 $\%$ CI: 34, $77 \%$ ). Median time to complete remission was 8.5 months (range 2 to 21 months). One of the patients who did not meet the criteria for complete remission 
because of persistent hematuria ( $100 \mathrm{RBC} / \mathrm{hpf})$ and proteinuria (1.5 gram per gram creatinine), and therefore did not count in our analysis as a responder, was believed to be in actual remission as his abnormal urinary findings were considered to be due to a renal cyst and other markers of lupus activity normalized including serum creatinine.

\section{Secondary outcome measures:}

Fifteen cases (71\%) achieved at least partial remission (95\% CI: 48, $88 \%$ ) over a median time period of 4 months (range 1 to 16 months). Three patients who did not achieve partial remission with MMF were switched to monthly intravenous cyclophosphamide after 3, 4 and 7 months. None of these achieved at least partial remission with cyclophosphamide either.

There was clinically and statistically significant improvement in the levels of urine protein, serum albumin, complement components $\mathrm{C} 3$ and $\mathrm{C} 4$ and anti DNA antibody levels at 3 months. The improvement continued progressively through the $6^{\text {th }}$ month and was sustained through the end of MMF therapy and at last follow up (last evaluation during the study period after discontinuing MMF). There was no clinically or statistically significant change in the counts of total white blood cells, neutrophils, lymphocytes or platelets throughout the study duration. There was a trend toward improved serum creatinine and hemoglobin levels, but these changes did not reach statistical significance (Table 7). 


\begin{tabular}{|c|c|c|c|c|c|c|c|c|c|}
\hline \multicolumn{10}{|c|}{ Table 7: Laboratory values (Median) over time } \\
\hline \multirow[t]{2}{*}{ Variable } & \multirow{2}{*}{ Baseline } & \multicolumn{2}{|c|}{ At 3 months } & \multicolumn{2}{|c|}{ At 6 months } & \multicolumn{2}{|c|}{$\begin{array}{l}\text { *At end of } \\
\text { MMF therapy }\end{array}$} & \multicolumn{2}{|c|}{$\begin{array}{c}* * \text { At last follow } \\
\text { up }\end{array}$} \\
\hline & & & $\mathrm{P}$ & & $\mathrm{P}$ & & $\mathrm{P}$ & & $\mathrm{P}$ \\
\hline WBC & 6.6 & 4.98 & 0.5700 & 6.1 & 0.7600 & 5.8 & 0.4000 & 6.8 & 0.7600 \\
\hline Lymphocytes & 0.9 & 0.8 & 0.9500 & 0.75 & 0.9800 & 1 & 0.8200 & 1 & 0.5300 \\
\hline Neutrophils & 4.6 & 4.75 & 0.9200 & 4.45 & 0.5500 & 3.9 & 0.1700 & 4.9 & 0.3300 \\
\hline Hemoglobin & 11.3 & 11.2 & 0.7000 & 12 & 0.9400 & 11.9 & 0.5300 & 12.2 & 0.3100 \\
\hline Platelet & 216 & 204 & 0.1900 & 251 & 0.1500 & 229 & 0.9800 & 234 & 0.7500 \\
\hline $\begin{array}{l}\text { Serum } \\
\text { creatinine }\end{array}$ & 1.1 & 0.95 & 0.0880 & 0.9 & 0.5300 & 0.9 & 0.8300 & 0.9 & 0.4500 \\
\hline UP:CR & 3.2 & 2.2 & 0.0003 & 1.9 & 0.0055 & 0.5 & 0.0028 & 0.6 & 0.0290 \\
\hline $\begin{array}{l}\text { Serum } \\
\text { Albumin }\end{array}$ & 2.2 & 2.9 & 0.0100 & 3.2 & 0.0026 & 3.7 & 0.0010 & 3.9 & 0.0017 \\
\hline Anti DNA & $1: 20$ & 0 & 0.0100 & 0 & 0.0140 & 0 & 0.0240 & 0 & 0.0350 \\
\hline $\mathrm{C} 3$ & 66 & 93.5 & 0.0016 & 97 & 0.0017 & 109 & 0.0010 & 105 & 0.0260 \\
\hline $\mathrm{C} 4$ & 13 & 19.5 & 0.0077 & 20.5 & 0.0080 & 19 & 0.0400 & 19 & 0.0880 \\
\hline
\end{tabular}

* Median 20 months. ** Median 26 months

The median time to normalization of serum creatinine was 1 month (range 0 to 2 months) in those whose creatinine was abnormal at baseline and improved with treatment $(\mathrm{N}=9)$. The median time to at least $30 \%$ reduction in proteinuria was 2 months (range 1 to 6 months) $(\mathrm{N}=16)$. The median time for either normalization of serum creatinine or at least $30 \%$ reduction in proteinuria was 1 month (range 1 to 6 months) $(\mathrm{N}=16)$. 
During treatment with MMF there was marked reduction in corticosteroid dose from a median dose of $30 \mathrm{mg}$ per day at the start to $15 \mathrm{mg}$ per day at 3 months ( $\mathrm{p}$ value $=0.001$ ) and to $5 \mathrm{mg}$ per day at 6 months $(\mathrm{p}$ value $=0.0007)($ Figure 1$)$.

Figure 1

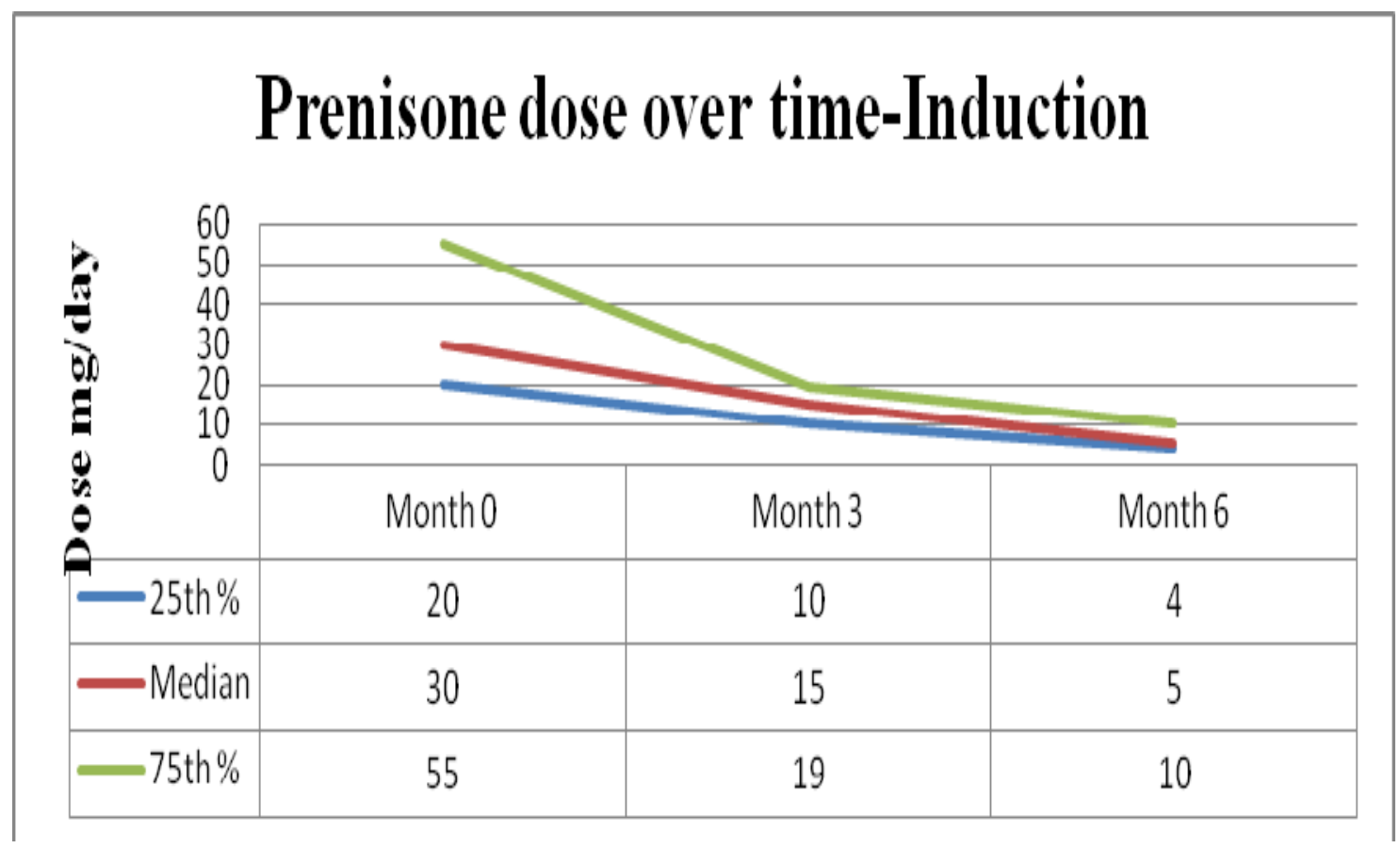

Tables 8 and 9 show association of several variables with complete remission, and tables 10 and 11 shows association of these variables with at least partial remission. An average MMF dose of at least 2 grams per day over the first 3 months was the only variable with statistically significant association with both complete remission and at least partial remission $(\mathrm{P}$ values $=0.02,0.0025$, respectively $)$. Of 17 patients who took at least 2 grams of MMF per day, $12(71 \%)$ achieved complete remission whereas none of 4 
patients who took less than 2 grams per day did; furthermore, 15 patients ( $88 \%)$ achieved at least partial remission. Duration of lupus nephritis correlated with complete remission but not with partial remission: of 15 patients with lupus nephritis duration of less than 12 months, 11 achieved complete remission while only one patient of 6 patients with lupus nephritis for more than 12 months did ( $\mathrm{p}$ value $=0.046$ ). When considering patients who had lupus nephritis for less than 12 months and took at least 2 grams per day of MMF (13 patients), 11 achieved complete remission compared to only one patient out of the 8 patients who did not meet both criteria $(\mathrm{p}$ value $=0.0022)$. History of diabetes was significantly associated with not attaining at least partial remission $(\mathrm{p}$ value $=0.015)$ but not with complete remission. Other baseline characteristics did not significantly predict response. Initial prednisone dose did not correlate with outcome. 


\section{Table 8: Categorical variables correlation with complete remission}

\begin{tabular}{|l|c|c|c|}
\hline \multicolumn{1}{|c|}{ Variable } & $\begin{array}{c}\text { Complete remission } \\
(\mathrm{N}=12) \\
\text { number (percentage) }\end{array}$ & $\begin{array}{c}\text { No complete remission } \\
(\mathrm{N}=9) \\
\text { number (percentage) }\end{array}$ & *P value \\
\hline Dose (at least 2 g per day) & $12(100 \%)$ & $5(56 \%)$ & $\mathbf{0 . 0 2 0}$ \\
\hline Race (African American) & $7(58 \%)$ & $4(44 \%)$ & 0.670 \\
\hline Sex (Male) & $1(8 \%)$ & $9(22 \%)$ & 0.550 \\
\hline **ACEI/ARB use & $10(83 \%)$ & $3(33 \%)$ & 0.490 \\
\hline Uncontrolled hypertension & $1(8 \%)$ & $3(33 \%)$ & 0.063 \\
\hline Diabetes & $0(0 \%)$ & $9(100 \%)$ & 0.490 \\
\hline Hydroxychloroquine use & $10(83 \%)$ & $5(56 \%)$ & $\mathbf{0 . 0 4 6}$ \\
\hline $\begin{array}{l}\text { Lupus nephritis duration } \\
\text { greater than 12 months }\end{array}$ & $1(8 \%)$ & & \\
\hline
\end{tabular}

*Fisher's exact test

** ACEI (angiotensin converting enzyme inhibitor), ARB (angiotensin receptor blocker) 


\section{Table 9: Continuous variables correlation with complete remission}

\begin{tabular}{|l|c|c|c|}
\hline \multicolumn{1}{|c|}{ Variable } & $\begin{array}{c}\text { Complete remission } \\
(\mathrm{N}=12) \\
\text { Median }\left(25^{\text {th }}, 75^{\text {th }} \%\right)\end{array}$ & $\begin{array}{c}\text { No complete remission } \\
(\mathrm{N}=9)\end{array}$ & *P value \\
\hline Age & $30.5(23,38.5)$ & $26(24,48)$ & 0.97 \\
\hline SLE duration & $5(3,63)$ & $27(22,79)$ & 0.27 \\
\hline Initial prednisone dose & $30(20,60)$ & $25(20,40)$ & 0.49 \\
\hline Serum Albumin & $2.1(2,2.95)$ & $2.6(2.2,2.7)$ & 0.51 \\
\hline Serum C3 (mg / dl) & $84(60,90)$ & $66(60,94)$ & 0.90 \\
\hline Serum C4 (mg / dl) & $15(12,20)$ & $13(10,18)$ & 0.52 \\
\hline Serum Creatinine (mg / dl) & $1.3(1.1,1.7)$ & $1(0.9,1.3)$ & 0.23 \\
\hline$* * U P:$ CR ratio (g / g) & $3(1.8,6.5)$ & $4.7(2.9,5.1)$ & 0.81 \\
\hline $\begin{array}{l}\text { Anti DNA antibody } \\
\text { (Units) }\end{array}$ & $1: 20(0,1: 160)$ & $0(0,1: 320)$ & 1.00 \\
\hline
\end{tabular}

*Wilcoxon ranked sum test

**UP: CR urine protein / creatinine 


\begin{tabular}{|l|c|c|c|}
\hline \multicolumn{1}{|c|}{ Table 10: Categorical variables correlation with at least partial remission } \\
\hline Variable & $\begin{array}{c}\text { At least partial } \\
\text { remission (N = 15) } \\
\text { number (percentage) }\end{array}$ & $\begin{array}{c}\text { No partial remission } \\
(\mathrm{N}=6) \\
\text { number (percentage) }\end{array}$ & *P value \\
\hline $\begin{array}{l}\text { Dose } \\
\text { (at least 2 grams per day) }\end{array}$ & $15(100 \%)$ & $2(33 \%)$ & 0.003 \\
\hline Race (African American) & $8(53 \%)$ & $3(50 \%)$ & 1.000 \\
\hline Sex (Male) & $2(13 \%)$ & $1(17 \%)$ & 1.000 \\
\hline *ACEI/ARB use & $13(87 \%)$ & $6(100 \%)$ & 1.000 \\
\hline Uncontrolled hypertension & $3(20 \%)$ & $1(17 \%)$ & 1.000 \\
\hline Diabetes & $0(0 \%)$ & $3(50 \%)$ & 0.015 \\
\hline Hydroxychloroquine & $13(87 \%)$ & $6(100 \%)$ & 1.000 \\
\hline $\begin{array}{l}\text { Lupus nephritis duration } \\
\text { greater than 12 months }\end{array}$ & $4(27 \%)$ & $2(33 \%)$ & 1.000 \\
\hline
\end{tabular}

*Fisher's exact test

** ACEI (angiotensin converting enzyme inhibitor), ARB (angiotensin receptor blocker) 


\begin{tabular}{|l|c|c|c|}
\hline \multicolumn{4}{|c|}{ Table 11: Continuous variables correlation with at least partial remission } \\
\hline \multicolumn{1}{|c|}{ Variable } & $\begin{array}{c}\text { At least partial } \\
\text { remission }(\mathrm{N}=15) \\
\text { Median }\left(25^{\text {th }}, 75^{\text {th }} \%\right)\end{array}$ & $\begin{array}{c}\text { No partial remission } \\
(\mathrm{N}=6) \\
\text { Median }\left(25^{\text {th }}, 75^{\text {th }} \%\right)\end{array}$ & $*$ P value \\
\hline Age & $28(23,39)$ & $25(24,43)$ & 0.93 \\
\hline SLE duration & $10(3,66)$ & $42(11,74)$ & 0.61 \\
\hline Initial prednisone dose & $30(17.5,60)$ & $27.5(21,37.5)$ & 0.71 \\
\hline Serum Albumin $(\mathrm{mg} / \mathrm{dl})$ & $2.1(2.1,2.6)$ & $2.7(2.6,2.8)$ & 0.41 \\
\hline Serum C3 (mg / dl) & $88(60,94)$ & $65(51,80)$ & 0.33 \\
\hline Serum C4 (mg / dl) & $15(13,20)$ & $11.5(10,13)$ & 0.12 \\
\hline Serum Creatinine (mg / dl) & $1.2(1,1.6)$ & $1(0.8,1.5)$ & 0.39 \\
\hline$* *$ UP: CR ratio $(\mathrm{g} / \mathrm{g})$ & $3.2(2.7,6.3)$ & $4(2.7,5)$ & 1.00 \\
\hline $\begin{array}{l}\text { Anti DNA antibody } \\
\text { (Units) }\end{array}$ & $0(0,1: 40)$ & $1: 160(1: 10,1: 1280)$ & 0.19 \\
\hline
\end{tabular}

* Wilcoxon rank sum test

**UP: CR urine protein / creatinine

\section{Maintenance therapy:}

Eleven patients out of the 12 reported above were maintained on MMF. An additional four patients were started on MMF after achieving complete remission with other regimens (one with cyclophosphamide, one with azathioprine, one with methotrexate and one with high dose corticosteroids alone). These 15 patients received MMF for a median period of 20 months (range 5 to 55 months). Median follow up was 26 months (range 10 to 68 months). Median average prednisone dose while taking MMF was minimal at $3 \mathrm{mg}$ per day $\left(25^{\text {th }}, 75\right.$ th $\%: 0,7.75 \mathrm{mg}$ per day). Two patients ( $13 \%, 95 \%$ CI: $\left.2,42 \%\right)$ 
experienced renal flares while taking MMF, at months 17 and 22 of MMF therapy; one of them had reduced the MMF dose to 1 gram per day. A third patient experienced a flare 17 months after discontinuing MMF.

\section{Adverse events (Table 12):}

Overall, 27 courses of MMF were received by 25 patients for remission induction and / or maintenance. The median duration of treatment was 19 months (range 0.2 to 55 months). The median follow up time was 26 months (range 10 to 76 months). The median of average dose was 2 grams per day (range: 0.7 to 2.9 grams per day). The most common adverse events, viral upper respiratory tract infections, upper gastrointestinal symptoms and diarrhea, were mild and transient and did not require change in therapy except in one patient, who did not tolerate dose escalation beyond 1 gram per day due to persistent diarrhea, nausea and vomiting. Two other patients discontinued MMF after 1 week and 1 month, because of severe nausea and hives, respectively. There were no serious pyogenic infections. Notably, 4 patients developed herpes zoster. No cases of amenorrhea were reported among 18 female patients younger than 50 years old. One patient, who was non adherent to medical treatment, died suddenly 3 months after discontinuing MMF with severe nephrotic syndrome and normal serum creatinine. One patient developed end stage renal disease within 5 months after failing both initial MMF and subsequent cyclophosphamide. 


\begin{tabular}{|l|c|c|}
\hline \multicolumn{3}{|l|}{ Table 12: Adverse Events. Duration of therapy (568.2 patient-month) } \\
\hline & No & $(\%)$ \\
\hline Serious infections* & 0 & $0 \%$ \\
\hline Pneumonia (treated with oral antibiotics) & 1 & $3.7 \%$ \\
\hline Tinea (nails) & 2 & $7 \%$ \\
\hline Cellulitis (Impetigo) & 1 & $3.7 \%$ \\
\hline Herpes zoster & 4 & $15 \%$ \\
\hline Mucocutaneous herpes & 2 & $7 \%$ \\
\hline Viral URIs & 10 & $37 \%$ \\
\hline GU infections & 4 & $15 \%$ \\
\hline Upper GI symptoms (nausea, vomiting, bloating, epigastric pain) & 9 & $33 \%$ \\
\hline Diarrhea & 6 & $22 \%$ \\
\hline Urticaria & 1 & $3.7 \%$ \\
\hline Amenorrhea & 0 & $0 \%$ \\
\hline
\end{tabular}

URI = upper respiratory infection, GI = gastrointestinal, GU = genitourinary.

* Serious infections were defined as those requiring intravenous antibiotic therapy or hospitalization.

\section{DISCUSSION}

Despite significant improvement in the outcome of lupus nephritis management over the past 3 decades, this serious manifestation of Systemic Lupus Erythematosus continues to be a major challenge to clinicians, with major impact on renal and overall survival in a 
usually young group of patients. The optimal therapeutic regimen for lupus nephritis and duration of treatment remain uncertain and the literature on lupus nephritis treatment is quite limited with a few randomized clinical trials including a few hundreds of patients. Corticosteroids alone, which are routinely used as a part of the initial treatment regimen, are inadequate for long term therapy. Moreover, the anti inflammatory effects of corticosteroids, although powerful, are quite non specific. Monthly intravenous cyclophosphamide, for at least 6 months, has become the "standard of care" for induction therapy for severe lupus nephritis but is potentially associated with serious toxicity and an imperfect effectiveness. Cyclophosphamide is a cytotoxic agent, with non specific effects that result in a wide spectrum of adverse effects. The newer drug, mycophenolate mofetil is not cytotoxic and has greater target specificity mainly affecting the lymphocytes. Initial data suggest better renal and overall outcomes compared to cyclophosphamide, with a better safety profile when used for induction and / or maintenance of remission. It has therefore emerged as another option for treatment of moderate to severe lupus nephritis.

Our study reports the cumulative experience with the use of MMF for induction and / or maintenance of remission of lupus nephritis from a single lupus clinic serving an urban population. African American and Hispanic patients, groups shown to have worse prognosis, constituted the largest proportion of our cohort; the majority of them had evidence of severe lupus nephritis. Most patients achieved at least partial remission when MMF was used initially for induction of remission. The effectiveness of MMF was most noticeable when treatment was initiated at an early stage and patients received a dose of at least 2 grams per day. 
The median time to complete remission was 8.5 months, which may be somewhat more delayed than many clinicians have appreciated. This observation is related to the fact that resolution of proteinuria, a criterion that is included in the definition of complete remission, usually takes much longer time than other criteria. We noted, however, that clear initial improvement in proteinuria is seen within a shorter time period (median 2 months). More importantly, the median time to normalization of serum creatinine was 1 month (range 0 to 2 months) in responders. Undoubtedly, the initial use of corticosteroid therapy contributes to the early response. Nevertheless, these observations may be helpful in setting expectations during treatment.

During maintenance therapy, only two patients experienced renal flares over a median follow up of 26 months (range 10 to 68 months) while taking MMF and a minimal prednisone dose. MMF was relatively safe and well tolerated, without occurrence of serious infections or death attributable to the drug.

\section{Limitations}

Some of the limitations of our study include its retrospective design and small sample size. The small number of patients with the outcome precluded risk adjustment with methods such as multivariate logistic regression. The results of our study therefore could be potentially confounded. Assignment of MMF for maintenance therapy was not random, which implies potential selection bias; however, there was virtually no selection issues during the induction phase, as the vast majority of patients were consecutive lupus nephritis patients seen by a single rheumatologist. Second, our outcomes were defined based on laboratory not pathological findings. As noted before, complete resolution of proteinuria often lags behind improvement of other measures of lupus nephritis 
remission. Moreover, persistent hematuria and even elevation of serum creatinine may sometimes reflect structural damage from scarring or vascular disease rather than active nephritis. Only two thirds of the patients underwent kidney biopsy, and activity and chronicity indices on renal biopsies were not evaluated. Finally, with the retrospective nature of the study, minor adverse events might have been under estimated, but this is less likely with serious events. It should also be mentioned that this study was partially supported by a grant from Aspreva Pharmaceuticals, which has the exclusive worldwide rights (excluding Japan) to develop and market CellCept ${ }^{\circledR}(\mathrm{MMF})$ in autoimmune disease applications.

\section{Strengths}

Nonetheless, a major strength of our study is that it presents data of longer duration than is available from previously published reports on MMF for induction of remission of lupus nephritis in the United States. The only data of longer duration came from Hong Kong (33), with a population that is racially different from our population. It reports the outcome of MMF use for continuous induction and maintenance treatment for lupus nephritis and provides data on the timing and long term rate of remission as well as predictors of remission with MMF use including the appropriate dose. It also reports the intermediate flare rate after induction with MMF. It clearly indicates that a later point than what has been usually used in recent clinical trials; i.e., 6 months, should be used to evaluate the effectiveness of an induction regimen for lupus nephritis. It also demonstrates the relative long term safety of this drug. This study reports recent data from real life experience from patients with severe disease and poor prognostic factors, including low socioeconomic status and non white race. 


\section{Conclusions}

In summary, this study suggests that MMF is an effective treatment option for both induction and long term maintenance of remission of lupus nephritis, with a relatively favorable safety profile. Early treatment with a dose of at least 2 grams per day is associated with a better outcome. As in all previous studies, some patients still did not achieve remission of their nephritis. While this may well be due to lack of efficacy of the drug, other factors such as patient adherence, disease co morbidities, duration of nephritis, irreversible damage and imperfect response criteria probably play roles of varying importance. Our data support the rationale for a controlled study to compare MMF and cyclophosphamide long term outcomes. Having multiple options to present to patients is always desirable. Whether MMF or another agent is chosen as the initial treatment, it is prudent that treatment is initiated as early as possible, adequate dose is used, signs of initial response be assessed early and change in strategy is promptly applied when indicated.

\section{DISCLOSURE:}

Partial support for this study was provided by a research grant from Aspreva Pharmaceuticals. 


\section{BIBLIOGRAPHY:}

1. Ward MM. Prevalence of physician-diagnosed systemic lupus erythematosus in the United States: results from the third national health and nutrition examination survey.

J Womens Health (Larchmt). 2004 Jul-Aug; 13(6):713-8.

2. Edworthy SM. Clinical Manifestations of Systemic Lupus Erythematosus. In: Ruddy S, Harris ED, Sledge CB, eds. Kelley's Textbook of Rheumatology. 7th ed. Philadelphia: WB Saunders; 2005:1039-53.

3. Seligman VA, Lum RF, Olson JL, Li H, Criswell LA. Demographic differences in the development of lupus nephritis: a retrospective analysis.Am J Med. 2002 Jun 15; 112(9):726-9.

4. Trager J, Ward MM. Mortality and causes of death in systemic lupus erythematosus. Curr Opin in Rheumatol 2001; 13: 345-351.

5. Flanc RS, Roberts MA, Strippoli GFM, Chadban SJ, Kerr PG, Atkins RC. Treatment of diffuse proliferative lupus nephritis: a meta-analysis of randomized controlled trials. Am J Kidney Dis 2004; 43: 197-208.

6. Korbet, SM, Lewis, EJ, Schwartz, MM, et al. Factors predictive of outcome in severe lupus nephritis. Lupus Nephritis Collaborative Study Group. Am J Kidney Dis 2000; 35:904.

7. Moore RA, Derry S. Systematic review and meta-analysis of randomized trials and cohort studies of mycophenolate mofetil in lupus nephritis. Arthritis Res Ther 2006; 8: R182

8. Contreras G, Pardo V, Leclercq B, et al. Sequential therapies for proliferative lupus nephritis. N Engl J Med 2004; 350:971-80.

9. Walsh, M, James, M, Jayne, D, et al. Mycophenolate mofetil for induction therapy of lupus nephritis: a systematic review and meta-analysis. Clin J Am Soc Nephrol 2007; 2:968.

10. Hochberg MC. Updating the American College of Rheumatology revised criteria for the classification of systemic lupus erythematosus [letter]. Arthritis Rheum 1997; 40:1725.

11. Tan EM, Cohen AS, Fries JF, Masi AT, McShane DJ, Rothfield NF, et al. The 1982 revised criteria for the classification of systemic lupus erythematosus. Arthritis Rheum $1982 ; 25: 1271-7$.

12. Dooley MA, Aranow C, Ginzler EM. Review of ACR renal criteria in systemic lupus erythematosus. Lupus. 2004; 13(11):857-60.

13. Weening JJ, D'Agati VD, Schwartz MM, et al. The classification of glomerulonephritis in systemic lupus erythematosus revisited. Kidney Int. 2004; 65:521530. 
14. Fries JF, Porta J, Liang MH: Marginal benefit of renal biopsy in systemic lupus erythematosus. Arch Intern Med 1978; 138:1386.

15. Esdaile JM, MacKenzie T, Barre P, et al: Can experienced clinicians predict the outcome of lupus nephritis? Lupus 1992; 1:205.

16. Austin, HA 3d, Boumpas, DT, Vaughan, EM, Balow, JE. Predicting renal outcomes in severe lupus nephritis: Contributions of clinical and histologic data. Kidney Int 1994; 45:544.

17. Jennette, JC, Iskandar, SS, Dalldorf, FG. Pathologic differentiation between lupus and nonlupus membranous glomerulopathy. Kidney Int 1983; 24:377.

18. Adu, D, Williams, DG, Taube, D, et al. Late onset systemic lupus erythematosus and lupus-like disease in patients with apparent idiopathic glomerulonephritis. Q J Med 1983; $52: 471$.

19. Chan, TM, Tse, KC, Tang, CS, et al. Long-term outcome of patients with diffuse proliferative lupus nephritis treated with prednisolone and oral cyclophosphamide followed by azathioprine. Lupus 2005; 14:265.

20. Moroni G, Quaglini A, Maccario M, Banfi G, Ponticelli C. 'Nephritic flares' are predictors of bad long-term renal outcome in lupus nephritis. Kidney Int 1996; 50: 2047 2053.

21. Ginzler EM, Dooley MA, Aranow C, Kim MY, Buyon J, Merrill JT, Petri M, Gilkeson GS, Wallace DJ, Weisman MH, Appel GB. Mycophenolate mofetil or intravenous cyclophosphamide for lupus nephritis. N Engl J Med. 2005 Nov 24; 353(21):2219-28.

22. Chan, TM, Li, FK, Tang, CS, et al. Efficacy of mycophenolate mofetil in patients with diffuse proliferative lupus nephritis. Hong Kong-Guangzhou Nephrology Study Group. N Engl J Med 2000; 343:1156.

23. Boumpas, DT, Austin, HA 3d, Vaughn, EM, et al. Controlled trial of pulse methylprednisolone versus two regimens of pulse cyclophosphamide in severe lupus nephritis. Lancet 1992; 340:741.

24. Chagnac, A, Kiberd, BA, Farinas, MC, et al. Outcome of the acute glomerular injury in proliferative lupus nephritis. J Clin Invest 1989; 84:922.

25. Rhen, T, Cidlowski, JA. Antiinflammatory action of glucocorticoids--new mechanisms for old drugs. N Engl J Med 2005; 353:1711.

26. Illei GG, Austin III HA, Crane M et al. Combination therapy with pulse cyclophosphamide plus pulse methylprednisolone improves long-term renal outcome without adding toxicity in patients with lupus nephritis. Ann Intern Med 2001; 135: 248257. 
27. Gourley, MF, Austin, HA III, Scott, D, et al. Methylprednisolone and cyclophosphamide, alone or in combination, in patients with lupus nephritis. A randomized, controlled trial. Ann Intern Med 1996; 125:549.

28. McCune, WJ, Golbus, J, Zeldes, W, et al. Clinical and immunologic effects of monthly administration of intravenous cyclophosphamide in severe systemic lupus erythematosus. N Engl J Med 1988; 318:1423.

29. Jonsson CA, Carlsten H. Mycophenolic acid inhibits inosine 5'-monophosphate dehydrogenase and suppresses production of pro-inflammatory cytokines, nitric oxide, and LDH in macrophages. Cell Immunol. 2002 Mar-Apr; 216(1-2):93-101.

30. Allison AC, Eugui EM. Mycophenolate mofetil and its mechanisms of action. Immunopharmacology 2000; 47: 85-118

31. Morath C, Schwenger V, Beimler J, Mehrabi A, Schmidt J, Zeier M, Muranyi W. Antifibrotic actions of mycophenolic acid. Clin Transplant. 2006; 20 Suppl 17:25-9.

32. Carr SF, Papp E, Wu JC et al. Characterization of human type I and type II IMP dehydrogenases. J Biol Chem 1993; 268:27286-27290

33. Chan TM, Tse KC, Tang CSO, Mok MY, Li FK. Long-term study of mycophenolate mofetil as continuous induction and maintenance treatment for diffuse proliferative lupus nephritis. J Am Soc Nephrol 2005;16: 1076-84.

34. Neylan J; for the US Renal Transplant Mycophenolate Mofetil Study Group: Immunosuppressive therapy in high-risk transplant patients: Dose-dependent efficacy of mycophenolate mofetil in African-American renal allograft recipients. Transplantation 64: $1277-1282,1997$

35. Bullingham RE, Nicholls AJ, Kamm BR. Clinical pharmacokinetics of mycophenolate mofetil. Clin Pharmacokinet. 1998; 34:429-455.

36. Kasitanon N, Petri M, Haas M, Magder LS, Fine DM. Mycophenolate mofetil as the primary treatment of membranous lupus nephritis with and without concurrent proliferative disease: a retrospective study of 29 cases. Lupus. 2008; 17(1):40-5.

37. Borba EF, Guedes LK, Christmann RB, Figueiredo CP, Gonçalves CR, Bonfá E. Mycophenolate mofetil is effective in reducing lupus glomerulonephritis proteinuria. Rheumatol Int. 2006 Oct; 26(12):1078-83. Epub 2006 May 31.

38. Cross J, Dwomoa A, Andrews P, Burns A, Gordon C, Main J, Mathieson P, O'Donoghue D, Jayne D; Renal Association Clinical Trials Subcommittee. Mycophenolate mofetil for remission induction in severe lupus nephritis. Nephron Clin Pract. 2005; 100(3):c92-100.

39. Ong LM, Hooi LS, Lim TO, Goh BL, Ahmad G, Ghazalli R, Teo SM, Wong HS, Tan SY, Shaariah W, Tan CC, Morad Z. Randomized controlled trial of pulse intravenous 
cyclophosphamide versus mycophenolate mofetil in the induction therapy of proliferative lupus nephritis. Nephrology (Carlton). 2005 Oct; 10(5):504-10.

40. Kapitsinou PP, Boletis JN, Skopouli FN, Boki KA, Moutsopoulos HM. Lupus nephritis: treatment with mycophenolate mofetil. Rheumatology (Oxford). 2004 Mar;43(3):377-80.

41. Li L, Wang H, Lin S, Et Al. Mycophenolate mofetil treatment for diffuse proliferative lupus nephritis: a multicenter clinical trial in China. Zhonghua Nei Ke Za Zhi. 2002 Jul; 41(7):476-9.

42. Hu W, Liu Z, Chen H, Tang Z, Wang Q, Shen K, Li L. Mycophenolate mofetil vs cyclophosphamide therapy for patients with diffuse proliferative lupus nephritis. Chin Med J (Engl). 2002 May; 115(5):705-9.

43. Illei, GG, Takada, K, Parkin, D, et al. Renal flares are common in patients with severe proliferative lupus nephritis treated with pulse immunosuppressive therapy: long-term followup of a cohort of 145 patients participating in randomized controlled studies. Arthritis Rheum 2002; 46:995-1002.

44. Grootscholten, C, Berden, JH. Discontinuation of immunosuppression in proliferative lupus nephritis: is it possible? Nephrol Dial Transplant 2006; 21:1465.

45. Zhu B, Chen N, Lin Y, Ren H, Zhang W, Wang W, Pan X, Yu H. Mycophenolate mofetil in induction and maintenance therapy of severe lupus nephritis: a meta-analysis of randomized controlled trials. Nephrol Dial Transplant. 2007 Jul; 22(7):1933-42.

46. Schnitzler MA, Craig KE, Hardinger KE, Lowell JA, Brennan DC. Mycophenolate mofetil is associated with less death with function than azathioprine in cadaveric renal transplantation. Nephrol Dial Transplant 2003; 18: 1197-1200.

47. Shimuzi H, Takahashi M, Takeda S-I et al. Mycophenolate mofetil prevents transplant arteriosclerosis by direct inhibition of vascular smooth muscle cell proliferation. Transplantation 2004; 77: 1661-1667

48. Tse KC, Li FK, Tang S, Tang CS, Lai KN, Chan TM. Angiotensin inhibition or blockade for the treatment of patients with quiescent lupus nephritis and persistent proteinuria. Lupus. 2005; 14(12):947-52.

49. Kasitanon N, Fine DM, Haas M, et al. Hydroxychloroquine use predicts complete renal remission within 12 months among patients treated with mycophenolate mofetil therapy for membranous lupus nephritis. Lupus. 2006; 15(6):366-70.

50. Dooley, MA, Hogan, S, Jennette, C, Falk, R. Cyclophosphamide therapy for lupus nephritis: Poor renal survival in black Americans. Kidney Int 1997; 51:1188.

51. Alarcon, GS, McGwin, G Jr, Bastian, HM, et al. Systemic lupus erythematosus in three ethnic groups. Predictors of early mortality in the LUMINA cohort. LUMINA Study Group. Arthritis Rheum 2001; 45:191. 
52. Contreras, G, Lenz, O, Pardo, V, et al. Outcomes in African Americans and Hispanics with lupus nephritis. Kidney Int 2006; 69:1846.

53. Barr, RG, Seliger, S, Appel, GB, Zuniga, R. Prognosis in proliferative lupus nephritis: The role of socio-economic status and race/ethnicity. Nephrol Dial Transplant 2003; 18:2039.

54. Korbet SM, Schwartz MM, Evans J, Lewis EJ; Collaborative Study Group. Severe lupus nephritis: racial differences in presentation and outcome. J Am Soc Nephrol. 2007 Jan;18(1):244-54.

55. Flower C, Hennis A, Hambleton IR, Nicholson G. Lupus nephritis in an Afro Caribbean population: renal indices and clinical outcomes. Lupus. 2006; 15(10):689-94.

56. Faurschou M, Starklint H, Halberg P, Jacobsen S. Prognostic factors in lupus nephritis: diagnostic and therapeutic delay increases the risk of terminal renal failure. $\mathrm{J}$ Rheumatol. 2006 Aug; 33(8):1563-9.

57. Mok CC, Wong RW, Lau CS. Lupus nephritis in Southern Chinese patients: clinicopathologic findings and long-term outcome. Am J Kidney Dis. 1999 Aug; 34(2):315-23.

58. Contreras, G, Pardo, V, Cely, C. Factors associated with poor outcomes in patients with lupus nephritis. Lupus 2005; 14:890.

59. Esdaile, JM, Joseph, L, Mackenzie, J, et al. The benefit of early treatment with immunosuppressive agents in lupus nephritis. J Rheumatol 1994; 21:2046. 